\title{
Attitudes towards breast-feeding among a sample of Chinese mothers living in Ireland
}

\author{
Q. Zhou, K. M. Younger and J. M. Kearney \\ School of Biological Sciences, Dublin Institute of Technology, Kevin Street, Dublin 8, Republic of Ireland
}

In recent years breast-feeding has become the focus of public health in Ireland. Previous research has reported significant differences in breast-feeding initiation rates among Irish mothers $(47.1 \%)$ and non-Irish mothers $(79.6 \%)$ living in Ireland ${ }^{(1)}$. While attitudes towards breast-feeding among Irish mothers have been previously described ${ }^{(2)}$, such information on non-nationals is lacking, particularly among Chinese residing in Ireland. The present study was undertaken to fill this information gap, describing the maternal attitudes towards breastfeeding among Chinese mothers living in Ireland.

A cross-sectional self-administrated survey was conducted. Questionnaires (written in Chinese) were distributed to the Chinese mothers, mainly via Chinese supermarkets and Chinese language schools in Ireland. Quantitative data were obtained from 343 mailed questionnaires.

Participants were mainly born in mainland China (80.6\%), aged between 30 years and 39 years (48.7\%), had tertiary education (50.4\%) and had been in Ireland for $>5$ years $(69.6 \%)$. Although $76.7 \%$ of the mothers had breast-fed their child, only thirteen mothers $(4.9 \%$ of the breast-feeding mothers) exclusively breast-fed until 3 months. The majority of the Chinese mothers were aware of the benefit and advantages of breast-feeding (Table). Most of the subjects $(78.7 \%$ ) believed that breast-milk could be enriched by consuming a special diet. Furthermore, some traditional Chinese food was largely believed $(82.9 \%)$ to be able to help improve breast-milk production. Meanwhile, some misconceptions of breast-feeding were prevalent. Over $58 \%$ of the subjects agreed that the mother should not breastfeed if she catches a cold. Also, approximately half the subjects agreed that infant formula should be fed to all newborns until their mother's milk comes in.

Table. Percentage of participants ( $n$ 343) who agreed or disagreed with the following statements (the advantages of breast-feeding)

\begin{tabular}{|c|c|c|c|}
\hline & $\begin{array}{l}\text { Strongly agree } \\
\text { or agree }\end{array}$ & $\begin{array}{l}\text { Strongly disagree } \\
\text { or disagree }\end{array}$ & Neither \\
\hline A breast-fed baby is likely to have fewer infections than a formula-fed baby & 60.2 & 12.3 & 27.6 \\
\hline Breast-milk is the ideal food for babies & 82.7 & 2.9 & 14.4 \\
\hline $\begin{array}{l}\text { Breast-feeding provides health benefits for infants that cannot be } \\
\text { provided by formula milk }\end{array}$ & 78.0 & 4.7 & 17.3 \\
\hline
\end{tabular}

The cultural belief of the importance of the special Chinese diet was widely accepted among Chinese mothers living in Ireland. Aside from certain cultural influences, some misconceptions of breast-feeding practices should be corrected to ensure a higher exclusive breastfeeding rate among the Chinese.

1. Tarrant RC \& Kearney JM (2008) Proc Nutr Soc 67, 371-380.

2. Zhou Q, Younger KM \& Kearney JM (2008) Proc Nutr Soc 67, E432. 